\title{
SOME BIOLOGICAL CONSIDERATIONS IN THE TREATMENT OF GONORRHOEA, AND THEIR PRACTICAL APPLICATION
}

\author{
By A. KISSMEYER, M.D. (Copenhagen)
}

THE effect that we wish to obtain in our local treatment of gonorrhœea is two-fold: on the one hand we seek to destroy the gonococcus in the tissues, on the other we aim to stimulate the vital protective power of the organism against the microbe. For some biologists the former object is the most important, while others attribute the main effect of our therapy to the influence on the tissues and the inflammatory process there, regarding the direct anti-microbial activity only as secondary. In conformity with the principle of directly attacking the microbes, a great proportion of venereologists are following the old method of treatment with bactericidal compounds, particularly the silver and silver-protein preparations advocated by the Neisser school. Against this bacteriological method a more "physiological" principle is favoured by quite a number of therapists, especially in France and England, who practise a less-directly microbicidal but a more tissue-stimulating and "draining" method. As the type of the first-named method we have urethral injections of protargol and albargin (I am speaking here only of male gonorrhœa), while the other is represented by Janet's irrigation method, supplemented during recent years by the parenteral application of vaccine, protein, glucose, etc.

I think that the truth, as is often the case, lies between these two points of view, or, better, in a combination of both. While I do not deny that the purely anti-microbial method has often paid too little attention to the physiological condition of the tissue in such an infectious disease as gonorrhœa, or that the series of preparations, mostly silver-protein compounds, which form the basis of this method, have been empirical and for the most part only 


\section{BRITISH JOURNAL OF VENEREAL DISEASES}

variations of already well-known chemical products, nevertheless it seems illogical to treat a localised infection only by the "indirect" method when we possess at least one chemical-silver-which has an undeniable effect on the specific microbe. The chemical must, however, be applied in such a form that it penetrates deeply into the tissue and is non-irritating, or as little irritating as possible. Many of the silver-protein preparations have an astringent effect, which is undesirable in a preparation which has to be used for a fresh infectious inflammation. It is therefore very remarkable that in many of the preparations this property is emphasised by the chemical manufacturers as an especially praiseworthy one, showing how very little regard they have for the physiological processes at work in inflammation. In this respect the hyperæmia-producing and the drainage-promoting method of Janet is preferable as having a good influence on the inflammatory process. Further, the investigations of Jacobsohn and Langer, Haxthausen and others have shown that the penetrating power of the silver-proteins is rather less than that of silver nitrate solution, while the highly-interesting investigations of v. Neergaard showed the absolutely therapeutic worthlessness of the undissociated silver in these preparations. Only the dissociated $\mathrm{Ag}$ is dynamically active, and the content of Ag-ions in most of the manufactured preparations is very small.

The old idea of the supremacy of the silver-proteins is not scientifically tenable ; also the Ag-ions in these when in contact with the lymph of the mucous membrane must form $\mathrm{AgCl}_{2}$ and $\mathrm{NaAgCl}_{2}$, which salts are not insoluble, but discharge Ag-ions into the tissue. Thus the mode of action of silver is always through the formation of $\mathrm{AgCl}_{2}$ and complex Ag-Na salts. This is a fundamental biological rule.

An anti-gonorrhœal preparation which observes the physiological and physico-chemical conditions present in a gonorrhœal inflammation must be deeply penetrating and have a sufficient content of dissociated, dynamically active $\mathrm{Ag}$, together with an effect on the inflammatory processes in promoting hyperæmic activity and washing out of the tissues. The way to obtain at the same time a penetration of the active agent and an effective washing out of the tissue is by an increased diffusion in the mucous membrane and submucous tissue. The most effective 


\section{TREATMENT OF GONORRHEA}

method of stimulating an increase in the flow of lymph is to attack one or more of the physiological constants of the organism, and thus to "break the physiological balance." The tissues must seek to re-establish the physiological balance and will therefore initiate a process of regulation. The attack by the chemical will be followed by a counterattack on the part of the tissues. If the provocative agent, in the case of the medicament in the urethra, is of a sufficiently potential activity to be a match for the counter-attack of the organism, the regulating measures will continue, and the conditions for drainage of the tissues are created.

The points on which such attacks may be most effectively conducted are the physiological salt concentration and hydrogen-ion concentration of the lymph, which are typical and constant. If the injected liquid combines a high osmotic pressure with a great potential acidity, the tissues will be forced by two processes to institute regulatory measures. The high osmotic pressure will occasion a lively lymph stream, and this will continue so long as a difference in osmotic pressure exists between the lymph and the liquid in the urethra. The potential acidity will occasion an attraction of alkali from the tissues. Working together, these two factors will occasion a highly-increased diffusion. By this the precipitating and astringent effect of the silver will be counteracted, and from the precipitate of silver-protein and $\mathrm{AgCl}$, formed superficially in the mucous membrane, the silver will be sucked down into the deeper layers of the tissue by the setting up of a dilution in loco; the precipitate will be of a less compact nature and take place deeper in the mucous membrane. If this theoretical supposition is right, a higher concentration than is generally used could be supported. Practical experience has shown that this is the case. Investigations in collaboration with the chemist, Gad Andresen, led to the production of a new chemical synthetical compound, argentum-nitricum-citricum " Gea,"

$$
\mathrm{C}_{240} \mathrm{H}_{278} \mathrm{O}_{280} \mathrm{Na}_{40} \mathrm{Ag} \text {, }
$$

a very labile salt that does not support precipitation or desiccation. A solution of this salt with constant hydrogen ion concentration, containing $0^{\circ}$ OOOI molar argentumnitricum-citricum per cubic centimetre, is called Citragan, "Gea." It contains 0.27 mgrm. Ag per cubic centimetre. 


\section{BRITISH JOURNAL OF VENEREAL DISEASES}

Its highly-potential acidity and a high osmotic pressure make it able to set up a very active diffusion in the tissues. The Ag is very loosely combined in the salt. Its content of active $\mathrm{Ag}$ is a little higher than that of a $0 \cdot 3$ per cent. protargol solution; yet it is tolerated by the mucous membrane in fresh, acute gonorrhœa in the male without any pain or bleeding. This is an argument in favour of the justice of the theory ; a lively diffusion with dilution in loco must take place.

This new chemical product combines a series of properties all of which are useful in the treatment of gonorrhœa, a high content of dissociated silver, a favourable influence on the reactive processes in the organism, especially on the diffusion in the tissues, which occasions an outwashing of these, together with a dilution in loco of the injected liquid. These are qualities which are useful in all cases where an anti-bacterial treatment is indicated; the therapeutic principle has not only value in the treatment of gonorrhœa.

As we wanted to work out the gonorrhœa therapy specially after this principle (and first only in the male), we wished to complete the urethral injections with drainage by the Janet method in cases where this treatment was preferable. While some venereologists prefer the purely drainage principle in gonorrhœal urethritis, others regard this only as complementary to urethral injections in cases of posterior complications. The lavage, by an average pressure of I metre, is mostly intended for treatment of the mucous membrane in the posterior part of the urethra, or in the bladder-and for this purpose Citragan possesses many advantages, as it produces a hyperæmia of the mucous membrane and an outwashing of the tissues, together with an anti-bacterial effect that the preparations mostly used for this treatment do not possess.

The solution that we prepare for this purpose is a rather concentrated one, so that 30 c.c. may, with 500 c.c. distilled water, give a liquid of the same osmotic pressure and hydrogen ion-concentration as Citragan, with an Agcontent corresponding to about I : I0,000.

But also in the anterior treatment we wished to improve the action on the mucous membrane by making the effect more lasting and effective. Such a continuous treatment by means of " bougies," or "styli," in the urethra has already been tried, especially in gonorrhœa of women, but 


\section{TREATMENT OF GONORRHEA}

also in male urethritis. The bougies manufactured hitherto, however, have been of a consistence which had little regard to the object of the treatment. None of them were really soluble and absorbable, so the first problem we had to settle was to find something that was absolutely soluble and could be absorbed by the mucous membrane, of an elastic and plastic consistency and in which the Citragan could be incorporated without loss of its special characteristics. The task was most difficult, but Mr. Gad Andersen succeeded in preparing a gelatinous mass by means of which we could manufacture " styli " containing Citragan with an even greater content of $\mathrm{Ag}$ (I.27 mgrm. per cubic centimetre), which was made possible by the action of the jelly as protective colloid. By means of those "styli Citragani" it is possible to institute a permanent or depôt-treatment that can be combined with the anterior injections, or with irrigations, and can be used in complications such as epididymitis or prostatitis. It seems to me of particular value that the irrigations which can generally be carried out only once a day (in the dispensary or hospital) can be supplemented by a more permanent anti-gonococcal depôt-treatment of the urethritis. It will surely shorten the course of the disease.

About I20 patients have so far been treated with Citragan. In the first 50 , which were treated only with the solution, 44 per cent. were cured in four weeks or less ; 34 per cent. in four to eight weeks ; 16 per cent. in eight to twelve weeks, and after that term there remained only 6 per cent. I am now treating all fresh urethritis with injections combined with styli, and this treatment is not only supported without any inconvenience from the beginning of the infection, but is also giving results that promise a much quicker cure of fresh gonorrhœa, about 60 per cent. having terminated the treatment in less than four weeks. Microscopical examination shows that the gonococci generally disappear in a week or less and do not reappear during the rest of the treatment. The films very soon show a high percentage of epithelial cells, and the number of epithelial cells generally increases during the treatment.

I think that this treatment should make it possible to abbreviate the course of male gonorrhœea; it is based on the physiological and physico-chemical phenomena 


\section{BRITISH JOURNAL OF VENEREAL DISEASES}

present in gonorrhœal infection, and does not damage the mucous membrane but aids it in the fight against the microbes. As my personal opinion, I may insist on the treatment with injections combined with styli four to five times a day in fresh urethritis, or with styli alone in complications with epididymitis and prostatitis. In posterior urethritis I would prefer a combination with Janet lavages, using the Citragan solution already named. In a further publication I shall supplement this more theoretical communication by putting forward further clinical information; in this article I would only invite attention to this preparation as a new one, which breaks with the old ideas of the protein-silver preparations, and which is based on physiological principles. 